\title{
Introduction to the Proceedings of the Avian Genomics and Gene Ontology Annotation Workshop
} Susan M Bridges*1,3,4, Shane C Burgess $2,3,4$ and Fiona M McCarthy²,3,4

Address: ${ }^{1}$ Department of Computer Science and Engineering, Box 9637, Mississippi State University, Mississippi State, MS 39762, USA, ${ }^{2}$ Department of Basic Sciences, College of Veterinary Medicine, Mississippi State University, Mississippi State, MS 39762, USA, ${ }^{3}$ Institute for Digital Biology, Mississippi State University, Mississippi State, MS 39762 and ${ }^{4}$ Life Science and Biotechnology Institute, Mississippi State University, Mississippi State, MS 39762, USA

Email: Susan M Bridges* - bridges@cse.msstate.edu; Shane C Burgess - burgess@cvm.msstate.edu;

Fiona M McCarthy - fmccarthy@cvm.msstate.edu

* Corresponding author

from Avian Genomics Conference and GO Annotation Workshop Starkville, MS, USA. 19-22 May 2008

Published: 14 July 2009

BMC Genomics 2009, I0(Suppl 2):II doi:I0.1I86/I47I-2164-I0-S2-II

This article is available from: http://www.biomedcentral.com/I47I-2/64/I0/S2/II

(c) 2009 Bridges et al; licensee BioMed Central Ltd.

This is an open access article distributed under the terms of the Creative Commons Attribution License (http://creativecommons.org/licenses/by/2.0), which permits unrestricted use, distribution, and reproduction in any medium, provided the original work is properly cited.

\begin{abstract}
The Avian Genomics Conference and Gene Ontology Annotation Workshop brought together researchers and students from around the world to present their latest research addressing the delivery of value from the billions of base-pairs of Archosaur sequence that have become available in the last few years. This editorial describes the conference itself and introduces the ten peerreviewed manuscripts accepted for publications in the proceedings. These manuscripts address issues ranging from the poultry industry view of USDA genomics policy to the genomics of a wide variety of Archeosaur species including chicken, duck, alligator, and condors and their pathogens.
\end{abstract}

\section{Introduction}

On May 19-20, 2008 the Mississippi State University Institute for Digital Biology hosted an international meeting entitled Delivering Value from Avian Genomes. The meeting was predicated on the fundamental need to deliver valuable knowledge from the investment in omic biology in avian species. In this respect it was preceded by the Blueprint for USDA Efforts in Agricultural Animal Genomics 2008-2017 [1] and by optimism from chicken production industries. Specific impetuses for this meeting were the aforementioned Blueprint, the sequencing of the zebra finch [2] and turkey genomes [3] and the US National Institute for Health's recognition of the impor- tance of avian species in human disease and for biomedical research http://www.nih.gov/science/models/gallus/.

This meeting was the fourth international meeting with a focus on chicken genomics. It followed the International Chicken Genome Workshop (Hinxton Genome Campus, Cambridge, UK, March 10-11, 2003) held just prior to sequencing; the International Meeting on the Chicken Genome (Stowers Institute of Medical Research, Kansas City, Mo, USA, April 29 to May 2, 2004) which focused on the initial examination of the released chicken genome sequence; the two Workshops on Chicken Genomics \& Development (Cold Spring Harbor Laboratories, NY, USA, May 8-11, 2005 and May $7-10,2006)$ which focused on the 
first genome-scale experimental work enabled by the genome sequence; and the International Chick Meeting (11-14 April 2007, Barcelona, Spain) with a major focus on genomics and development, the immune system and evolutionary biology.

The genomics meeting at Mississippi State University built on these previous meetings but focused on deriving value from the investments in genomics and functional genomics in the chicken as well as other avian genomics research. It was also the first such meeting to focus also on "avian" genome sequences other than chicken. From the manuscripts that follow it is clear that the combination of second generation sequencing technologies and the ability to leverage the investment in the chicken genome sequence has enabled Archosaur genomics (the diapsid reptiles represented by modern birds and crocodilians and including extinct non-avian dinosaurs, pterosaurs and relatives of crocodiles). It is also notable that, although the chicken genome "was sequenced" by 2004 [4], it still requires structural annotation, more targeted sequencing to elaborate specific areas, experimental validation and sequencing of the gene-rich micro-chromosomes that currently are not included in the genome sequence at all. It is expected that efforts to sequence the turkey and the zebra finch will not only benefit from the chicken genome but that these species will, in turn, enhance the chicken genome sequence annotation. It is also likely that second (and later)-generation sequencing technologies will help fill in our knowledge gaps in the next few years.

Concurrently with technology advances in genome sequencing there is clearly an understanding in the avian research communities that, with enormous increases in genomic data, we need to ensure that we do not lose sight of the fundamental scientific questions. With this in mind there has been an increase in specific practical, accessible and user-friendly computational resources and tools dedicated to avian omic-scale biology; these will be essential if the goals of the Blueprint for USDA Efforts in Agricultural Animal Genomics 2008-2017 [1] are to be achieved and for our avian models to fulfil their potential as biomedical research tools. The manuscripts in this BMC Genomics special supplement are those that were submitted, refereed and accepted for publication after this meeting. What is clear from these articles is the range and depth of the value that can be created now that the fundamental data source, along with computational tools built in the last five years, are available and democratizing the use this data.

\section{Proceedings summary}

The Avian Genomics Conference was organized by Susan M. Bridges and Shane C. Burgess. Members of the program committee were Parker Antin, University of Arizona,
David Burt, Roslin Institute, Edinburgh, Scotland, Youping Deng, University of Southern Mississippi, Mark Johnson, U.S. Army Center for Health Promotion and Preventative Medicine, Fiona McCarthy, Mississippi State University, Edward Perkins, U. S. Army Corps of Engineers Environmental Laboratory, and Carl Schmidt, University of Delaware. The Avian Gene Ontology (GO) Annotation Workshop was organized by Fiona M. McCarthy of Mississippi State University and members of the program committee were: Rama Balakrishana, Stanford University, Jennifer Clark, European Bioinformatics Institute, UK, Judith Blake, Jackson Laboratories, and Harold Drabkin, Jackson Laboratories.

The keynote speaker for the Avian Genomics Conference, Dr. Scott Edwards from Harvard University is internationally known for his ground-breaking research in the genomics based phylogenetics of many different avian species and reptiles including dinosaurs. One of the founders of the Gene Ontology (GO), Judith Blake of Jackson, Laboratories was the plenary speaker for the Avian GO Annotation Workshop.

A student poster competition was conducted and a panel of judges selected award winners. First place was awarded to Laura Lleras, King's College London, second place to Ang Li, University of Southern California, and third place tie to Catalina Tudor of the University of Delaware and Shyamesh Kumar of Mississippi State University.

Papers submitted for inclusion in the proceedings were peer-reviewed by two or more program committee members and other research area experts. The accepted papers demonstrate the breadth of research enabled by the availability of avian genomes. Papers have been grouped into several categories described in the following sections.

\section{Poultry genomics}

Janet Fulton [5] of Hy-Line International reviews the Blueprint for USDA Efforts in Agricultural Animal Genomics 2008-2017 [1] from a poultry industry perspective with a focus on the tools, resources, and technologies specifically required for chicken. Fulton contends that the Blueprint has a significant bias toward the cattle industry and highlights areas where approaches in the cattle industry such as SNP analysis do not have direct applicability for poultry. She provides an extensive discussion of infrastructure needs for poultry research ranging from animal resource populations to bioinformatics tools.

Behnam Abasht and colleagues [6] analyze characteristics required for Marker Assisted Selection (MAS) in commercial layer chicken populations. Effective MAS requires high linkage disequilibrium (LD) between markers and quantitative trail loci (QTL) and sustained marker-QTL 
LD over generations. Their study uses two different methods to assess the level and consistency of LD between SNPs to identify markers associated with egg-quality and egg-production phenotypes. Their results indicate that markers will retain high LD with linked QTL and be effective for MAS.

Tamsyn Crowley and colleagues [7] investigate the utility of whole genome chicken microarrays for cross-species analysis of other avian species including duck. They demonstrate that cross species hybridization ( $\mathrm{CSH}$ ) provides reliable signals and that whole genome long oligonucleotide chicken microarrays provide a valuable resource for studying gene expression in a range of avian species.

Bindu Nanduri and colleagues [8] study the transcriptional response of the gram-negative bacterial pathogen Pasteurella multiocida, the agent of fowl cholera in poultry, to sub-lethal doses of three different classes of antibiotics. They demonstrate common adaptive responses to antibiotic stress and also identify differences in the responses. Their systems biology analysis demonstrates both the possibilities and the challenges of modelling high throughput datasets in non-model avian bacteria.

\section{Bioinformatics resources}

The utility of the chicken and other avian genomes critically depends on the development of appropriate and specialized bioinformatics tools. Consistent and meaningful gene nomenclature fundamentally underpins bioinformatics analysis and David Burt and colleagues [9] report the formation of the Chicken Gene Nomenclature Committee (CGNC). The CGNC, in collaboration with the research community as a whole, will provide standardized nomenclature for the chicken genome that reliably links chicken genes across all databases follow nomenclature and associated guidelines established by the Human Genome Nomenclature Committee (HGNC).

Effective application of systems biology to emerging model species including avians requires extensive interaction data that are often unavailable. Jay Konieczka and colleagues [10] describe the open-source BioNetBuilder2.0 client-server Cytoscape [11] plugin that automatically integrates molecular interactions from all major public interaction databases and provides these directly to the user's Cytoscape environment. The article includes a detailed tutorial of all steps required in the analysis.

Using aquaporins as a case study, Raphael Isokpehi and colleagues [12] investigate how the integration of chicken and mammalian sequence, as well as gene expression resources, enable functional genomics research in both avian and mammalian species. To do so they demonstrate the types of hypotheses that can be generated by integrating a wide variety of on-line resources.

\section{Archeosaur genomics}

Previous international conferences dealing with avian genomics had focused almost exclusively on chicken. In contrast, the scope of Delivering Value from Avian Genomes was consciously expanded to include all avian species and related archosaurs such as crocodilians, lizards, and dinosaurs. Chapus and Edwards [13] use paired bacterial artificial chromosome (BAC) end sequences from the American alligator, painted turtle, emu and chicken to investigate patterns of sequence divergence, gene and retroelement content and microsynteny in Reptilia. Their results provide insights into the evolution of the lineage leading to chicken including the drastic reduction in genome size observed in birds.

Shan and colleagues [14] describe the development of a high quality BAC library for a second crocodilian, the Australian saltwater crocodile. They demonstrate the utility of the new resource for gene isolation, genome characterization, and comparative genomics.

Romanov and colleagues [15] demonstrate the application of genomic studies of wild birds to comprehensive conservation including deeper understanding of mechanisms affecting genetic variation, adaptation, and evolution. They provide case studies of genotyping a California condor resource population to provide an improved assessment of current population genetic variation and also genomic studies of the white-throated sparrows to understand evolution of natural populations.

\section{Competing interests}

The authors declare that they have no competing interests.

\section{Authors' contributions}

All authors served as co-editors of these proceedings and all authors helped write this introduction.

\section{Acknowledgements}

This meeting and the proceedings were made possible by a conference grant from the Mississippi State University Office of the President and by funding by NSF EPSCoR Grant (EPS-0556308 06040292) and NIH award number 5R24GM079326. Dr. Edward Perkins of the Environmental Laboratory of the U.S. Army Corps of Engineers Engineering Research and Development Center provided student travel awards to the conference. We also thank our peer reviewers for ensuring the high quality of the papers in the proceedings.

This article has been published as part of BMC Genomics Volume 10 Supplement 2, 2009: Proceedings of the Avian Genomics Conference and Gene Ontology Annotation Workshop. The full contents of the supplement are available online at http://www.biomedcentral.com/ $/ 47 \mid-2164 / 10$ ? issue=S2 


\section{References}

I. USDA Animal Genomics Strategic Planning Task Force. United States. Cooperative State Research Education and Extension Service: Blueprint for USDA efforts in agricultural animal genomics 20082017. Washington, DC U.S. Dept. of Agriculture, Agricultural Research Service, Cooperative State Research, Education, and Extension Service; 2007.

2. Clayton D, Arnold AP, W W, Jarvis E, Mello C, Burt DW, Ellegren $\mathrm{H}$ Proposal to Sequence the Genome of the Zebra Finch (Taeniopygia guttata). Submitted to NHGRI by the Zebra Finch Genome Consortium 2005.

3. Whyte B: Research consortium to sequence turkey genome. Virginia Polytechnic Institute and State University Press Release; 2008.

4. International Chicken Genome Sequencing Consortium: Sequence and comparative analysis of the chicken genome provide unique perspectives on vertebrate evolution. Nature 2004, 432(7018):695-716.

5. Fulton JE: USDA Animal Genomics Program: The view from the chicken coop. BMC Genomics 2009, I 0(Suppl 2):SI.

6. Abasht B, Beach E, Arango J, Settar P, Fulton JE, O'Sullivan NP, Hassen A, Habier D, Fernando RL, Dekkers JCM, et al.: Extent and consistency of linkage disequilibrium and identification of DNA markers for production and egg quality traits in commercial layer chicken populations. BMC Genomics 2009, I O(Suppl 2):S2

7. Crowley TM, Haring VR, Burggraaf S, Moore RJ: Application of Chicken Microarrays for Gene Expression Analysis in Other Avian Species. BMC Genomics 2009, I O(Suppl 2):S3.

8. Nanduri B, Shack LA, Burgess SC, Lawrence ML: The transcriptional response of Pasteurella multocida to three classes of antibiotics. BMC Genomics 2009, I 0(Suppl 2):S4.

9. Burt DW, Carrie W, Fell M, Law AS, Antin PB, Maglott DR, Weber [A, Schmidt C], Burgess SC, McCarthy FM: The Chicken Gene Nomenclature Committee Report. BMC Genomics 2009, I O(Suppl 2):S5

10. Konieczka JH, Drew K, Pine A, Belasco K, Davey S, Yatskievych T, Bonneau R, Antin PB: BioNetBuilder2.0: Bringing Systems Biology to Chicken and other Model Organisms. BMC Genomics 2009, I 0(Suppl 2):S6.

II. Cline MS, Smoot M, Cerami E, Kuchinsky A, Landys N, Workman C Christmas R, Avila-Campilo I, Creech M, Gross B, et al.: Integration of biological networks and gene expression data using Cytoscape. Nat Protoc 2007, 2( I 0):2366-2382.

12. Isokpehi RD, Rajnarayanan RV, Jeffries CD, Oyeleye T, Cohly HHP. Integrative Sequence and Tissue Expression Profiling of Chicken and Mammalian Aquaporins. BMC Genomics 2009, I O(Suppl 2):S7.

13. Chapus C, Edwards SV: Genome evolution in Reptilia: in silico chicken mapping of 12,000 BAC-end sequences from two reptiles and a basal bird. BMC Genomics 2009, I O(Suppl 2):S8.

14. Shan X, Ray DA, Bunge JA, Peterson DG: A bacterial artificial chromosome library for the Australian saltwater crocodile (Crocodylus porosus) and its utilization in gene isolation and genome characterization. BMC Genomics 2009, I O(Suppl 2):S9.

15. Romanov MN, Tuttle EM, Houck ML, Modi WS, Chemnick LG Korody ML, Stremel Mork EM, Otten C, Renner T, Jones KC, et al. The value of avian genomics to the conservation of wildlife. BMC Genomics 2009, I0(Suppl 2):SIO.

Publish with Bio Med Central and every scientist can read your work free of charge

"BioMed Central will be the most significant development for disseminating the results of biomedical research in our lifetime. "

Sir Paul Nurse, Cancer Research UK

Your research papers will be:

- available free of charge to the entire biomedical community

- peer reviewed and published immediately upon acceptance

- cited in PubMed and archived on PubMed Central

- yours - you keep the copyright
BioMedcentral 